\title{
Time to diabetic neuropathy and its predictors among newly diagnosed type 2 diabetes mellitus patients in Northwest Ethiopia
}

Sewnet Adem Kebede ${ }^{1^{*}}$ (10, Biruk Shalmeno Tusa ${ }^{2}$, Adisu Birhanu Weldesenbet ${ }^{2}$, Zemenu Tadesse Tessema ${ }^{1}$ and Tadesse Awoke Ayele ${ }^{1}$

\begin{abstract}
Introduction: Despite the high number of patients suffering from the negative impact of diabetic neuropathy (DN) in Ethiopia, evidence regarding the time to DN and its predictors are not well document in Ethiopia. Therefore, the current study aimed to determine time to DN and its predictors among newly diagnosed type 2 diabetes patients (T2DM) in North West Ethiopia.
\end{abstract}

Methods: Institutional based retrospective cohort study was conducted among 463 T2DM. Cox proportional hazard model was fitted to identify predictors of time to DN. The adjusted hazard ratio (AHR) with its 95\% confidence interval was used to declare the presence and strength of association.

Results: From a total 463 study participants, 77 (16.63\%), (95\% Cl 13.23\%, 20.03\%) had developed diabetic neuropathy. The median time to develop DN was 233.77 months. About 40 (51.95\%) diabetic neuropathy cases occurred within 6 years of diagnosis of diabetic mellitus. The incidence density was $2.01 / 100$ PY with $95 \% \mathrm{Cl}$ of $[1.60,2.53]$. In the multivariable Cox proportional hazard analysis; being aged 65-69 [AHR $=2.78 ; 95 \% \mathrm{Cl} 1.20,6.46]$, living with diabetes for less than 4 years $[A H R=3.77 ; 95 \% \mathrm{Cl} 1.82,7.76]$, having anaemia $[A H R=3.82 ; 95 \% \mathrm{Cl} 1.66,8.82]$ and having other complications $[\mathrm{AHR}=1.68 ; 95 \% \mathrm{Cl} 1.03,2.76$ were significant predictors of $\mathrm{DN}$.

Conclusion: More than half of diabetic neuropathy cases occurred within a short period of diagnosed with T2DM. Significant predictors for the time to DN were age, duration, having anaemia and other DM complication. Therefore, we recommend that early screening for DM and its complication for risky groups. While doing that due consideration should be assumed for old and anemic patients.

Keywords: Diabetic neuropathy, Type 2 diabetes mellitus, Ethiopia, Complication

\section{Introduction}

Diabetes mellitus (DM) is a metabolic disorder characterized by hyperglycemia and has an increasing trend globally. According to International Diabetes Federation (IDF) estimates in 2019 there are 463 million adults with diabetes worldwide. World Health Organization (WHO)

\footnotetext{
*Correspondence: sewnetme1@gmail.com

1 Department of Epidemiology and Biostatistics, Institute of Public Health, College of Medicine and Health Sciences, University of Gondar, Gondar, Ethiopia

Full list of author information is available at the end of the article
}

projection indicated that around 700 million people will suffer from DM by 2045 [1]. Diabetes mellitus is the fifth leading cause of death worldwide and is responsible for almost 3 million deaths annually. Diabetic neuropathy (DN) is one of the most common chronic and micro-vascular complications of DM [2].

Diabetic neuropathy (DN) is defined as signs and symptoms of peripheral nerve dysfunction in a patient with DM in whom other causes of peripheral nerve dysfunction have been excluded. It is a nerve damage related to chronically high blood sugar and diabetes. In the long 
run, it leads to numbness, loss of sensation, and sometimes pain in feet, legs, or hands. About $60 \%$ to $70 \%$ of all people with diabetes develop DN $[3,4]$.

Diabetic neuropathy is characterized by frequent hospitalization as compared to other complications of DM and also is the most frequent cause of non-traumatic amputation resulting in severe disability and reduced quality of life. It accounts for silent myocardial infarction and shortens the life expectancy resulting in death in $25-50 \%$ patients within 5-10 years of developing diabetic neuropathy. It can occur with both type 1 and type $2 \mathrm{DM}$ (T2DM) and a major risk factor for foot ulceration $[5,6]$.

The prevalence of DN is high in low resource setting particularly, sub-Saharan Africa due to late diagnosis, scarcity of screening and diagnostic resources and poor control of blood sugar [7]. The prevalence rates of $56.2 \%$ and $50.7 \%$ were reported from Yemen and Ghana, respectively $[8,9]$. In Ethiopia the prevalence of $53.6 \%$ from Jimma [10] and 52.2\% from Bahir Dar [11] were reported. The study showed that prevalence of $\mathrm{DN}$ is about $8 \%$ among newly diagnosed DM patients and greater than $50 \%$ among patients with longstanding disease [12].

Despite the high number of patients suffering from the negative impact of DN in Ethiopia, evidence regarding the time to DN and its predictors is not well document in Ethiopia. Therefore, the current study aimed to determine time to DN and its predictors among newly diagnosed type 2 diabetes patients in North West Ethiopia. The finding of the current study will be helpful for the timely identification and treatment of DN thereby to improve the extent of damage and disability.

\section{Methods}

\section{Study design, periods and settings}

An institutional based retrospective cohort study was conducted from March 1 to April 15, 2019 among patients diagnosed with T2DM from January 2001 to February 2019.

\section{Study population}

The current study included all patients who were newly diagnosed with T2DM during the follow-up visits from January 2001 to February 2019 at UGCSH. New T2DM diagnosed patients with $\mathrm{DN}$ at the time of the diagnosis and no baseline records were excluded from the study.

\section{Sample size determination}

The sample size was determined using the "powerSurvEpi" package of $\mathrm{R}$ software by considering Cox proportional hazard model assumptions. We assumed the probability of type I error $(\alpha) 0.05$, power of the study, $80 \%$ and the withdrawal probability of 0.1 which is the proportions of subjects expected to withdraw from the study. Accordingly, the total calculated sample size was 491.

\section{Operational definitions \\ Newly diagnosed type 2 diabetic patients}

Patients who were diagnosed for T2DM from January 2001 to February 2019.

\section{Diabetic neuropathy}

Diabetic neuropathy can be either small fiber neuropathy or large fiber neuropath. Small fiber neuropathy manifested by pain, tingling, paraesthesia and confirmed by pinprick and temperature examination. Large fiber neuropathy is manifested by numb feet and gait ataxia and confirmed by touch sensation by $10 \mathrm{~g}$ monofilament, vibration sense by biothesiometer and ankle reflex.

\section{Time to diabetic neuropathy}

Time difference between being diagnosed with T2DM to the development of diabetic neuropathy.

\section{Censored}

Patients who did not develop diabetic neuropathy or died or lost follow-up or transfer-out before developing diabetic neuropathy within the study period.

\section{The event of interest}

The experience of symptoms of diabetic neuropathy within the follow-up period.

\section{Other DM complication}

Having other diabetic complications like diabetic retinopathy, diabetic nephropathy, diabetic foot ulcer, peripheral arterial disease, stroke and chronic heart diseases.

\section{Measurement of variables and data collection methods}

Data for this study were collected from patient's routine records using a data extraction checklist. Data was extracted by reviewing DM registration book, patient intake form and follow-up card. Health management information system (HMIS) card number was used to identify individual patient cards. The dependent variable for this study was time to time to diabetic neuropathy. Independent variables like gender, age, duration of DM, hypertension, anaemia, other DM complications, baseline medication, Systolic Blood Pressure (SBP) and Diastolic Blood Pressure (DBP) were collected from patient cards.

\section{Data quality control methods}

To check the adequacy of the checklist, the preliminary review was conducted before the actual data collection period. Based on this, unavailable variables were 
excluded from the checklist. Data was collected by trained health care workers who are familiar with chronic disease. In addition, a random sample of data extracted was crosschecked for consistency. Strict supervision was taken by supervisors during data collection.

\section{Data processing and analysis}

The data were entered into Epi Info 7 and then exported to $\mathrm{R}$ statistical software 4.0.1 for further analysis. The incidence of diabetic neuropathy was calculated from the start of T2DM diagnosis until the last follow-up visit. Person-time at risk was measured starting from the time of T2DM diagnosis until each patient ended the followup. Time to diabetic neuropathy was estimated using Kaplan-Meier (KM) method and KM curve was used to compare survival time between groups of categorical variables. Before fitting cox proportional hazard model, proportional hazard assumptions (PHA) were checked by the Schoenfeld residual test and the results tell that the assumption of PHA is plausible at 5\% level of significance. The adjusted hazard ratio with its confidence interval was used to show the presence and strength of the association.

\section{Results}

\section{Characteristics of study participants}

A total of 463 newly diagnosed type $2 \mathrm{DM}$ patients were included in the analysis. Among these, 278 (60.04\%) of them were females, 107 (23.11\%) of them had hypertension and 37 (7.99\%) of them had anaemia. Regarding the baseline medication, 296 (63.93) study participants took one oral anti-diabetic agent, whereas $79(17.06 \%)$ of them took more than one oral anti-diabetic agent (Table 1).

\section{Time to diabetic nephropathy}

From a total 463 study participants, 77 (16.63\%), (95\% CI $13.23 \%, 20.03 \%$ ) had developed diabetic neuropathy with 3716.71 person-year (PY) of observations. The incidence density was $2.01 / 100$ PY with $95 \%$ CI of $[1.60,2.53]$. More than half (51.95\%) of the event of interest (diabetic neuropathy), were occurred with 6 years of diagnosis of diabetic mellitus.

By the end of the follow-up period, the cumulative probability of survival was 0.44 . The median survival time was 233.77 months which indicates the study was ended after $50 \%$ of the study subject develop diabetic neuropathy (Fig. 1). Furthermore, Kaplan-Meier survival estimate showed that hazards of developing diabetic neuropathy were higher among patients who had anaemia as compared to its counterparts (Fig. 2).

\section{Predictors of time to diabetic neuropathy}

Based on multivariable Cox-regression analysis, age, duration of DM, having anaemia and other complications were significant predictors of diabetic neuropathy among newly diagnosed type 2 DM patients at $p$ value 0.05 (Tables 1, 2).

Holding other variables constant, the hazard of diabetic neuropathy was increased by 2.78 times among newly diagnosed T2DM aged 65-59 than aged 45-49. Adjusting for other variables, the risks of developing diabetic neuropathy were increased by 3.82 and 1.68 times among newly diagnosed T2DM who had anemia and other DM complication, respectively.

The duration of DM was an important variable that showed significant association with diabetic neuropathy among newly diagnosed T2DM. Keeping other variable constant, the hazard of diabetic neuropathy was increased by 3.77 times among T2DM who had DM less than 4 years as compared to 5-9 years. In contrast, the risk diabetic neuropathy was decreased among T2DM who had DM for greater than 10 years as compared to those who lived with DM 5-9 years.

\section{Discussion}

Diabetic neuropathy is a well-known micro-vascular complication among T2DM resulted from chronic hyperglycaemia and is defined as the manifestation of peripheral nerve dysfunction in diabetics after the exclusion of other sources of causes [13]. As per the author's knowledge, no previous study was conducted to determine the time to DN and its predictors among newly diagnosed type 2 diabetes patients. That's why the present study intended to determine time to $\mathrm{DN}$ and its predictors among newly diagnosed type 2 diabetes patients in North West Ethiopia.

According to the current study, the proportions of newly diagnosed type 2 diabetes patients who have diabetic neuropathy were $16.63 \%$ [95\% CI 13.23\%, 20.03\%]. This finding is lower than the study conducted in Tanzania [14], Uganda [15], Pakistan [16] and Jordan [17]. This discrepancy might be due to the difference in health care systems that help to early diagnose diabetes and its complication.

In the current study, the duration of DM was an important variable that had a negative association with diabetic neuropathy among newly diagnosed T2DM. Furthermore, more than half of the event of interest (diabetic neuropathy), were occurring within 6 years of diagnosis of diabetes mellitus. Such findings tell us majority diabetic patients were diagnosed with diabetes mellitus in late time and they were at risk for developing diabetic neuropathy in early time. 
Table 1 Characteristics of study participants of newly diagnosed T2DM patients in UGCSH, January 2001-February 2019

\begin{tabular}{|c|c|c|c|c|}
\hline Variable & Event (\%) & Censored (\%) & Total $(n=463)$ & Percentage \\
\hline \multicolumn{5}{|l|}{ Gender } \\
\hline Female & 45 (16.2) & $233(83.8)$ & 278 & 60.04 \\
\hline Male & $32(17.3)$ & $153(82.7)$ & 185 & 39.96 \\
\hline \multicolumn{5}{|l|}{ Age } \\
\hline $30-34$ & $1(16.7)$ & $5(83.3)$ & 6 & 1.30 \\
\hline $35-39$ & $6(19.4)$ & 25 (80.6) & 31 & 6.70 \\
\hline $40-44$ & $6(12.0)$ & $44(88.0)$ & 50 & 10.80 \\
\hline $45-49$ & $10(11.9)$ & 74 (88.1) & 84 & 18.14 \\
\hline $50-54$ & $12(15.6)$ & $65(84.4)$ & 77 & 16.63 \\
\hline $55-59$ & $11(14.7)$ & $64(85.3)$ & 75 & 16.20 \\
\hline $60-64$ & $12(19.7)$ & 49 (80.3) & 61 & 13.17 \\
\hline $65-69$ & $14(31.1)$ & $31(68.9)$ & 45 & 9.72 \\
\hline$>70$ & $5(14.7)$ & 29 (85.3) & 34 & 7.34 \\
\hline \multicolumn{5}{|l|}{ Duration of DM } \\
\hline $0-4$ & 15 (18.3) & $67(81.7)$ & 82 & 17.71 \\
\hline $5-9$ & 35 (15.8) & $187(84.2)$ & 222 & 47.95 \\
\hline $10-14$ & $22(16.7)$ & $110(83.3)$ & 132 & 28.51 \\
\hline$>14$ & $5(18.5)$ & $22(83.4)$ & 27 & 5.83 \\
\hline \multicolumn{5}{|l|}{ Hypertension } \\
\hline Yes & $22(20.6)$ & $85(79.4)$ & 107 & 23.11 \\
\hline No & $55(15.4)$ & $301(84.6)$ & 356 & 76.89 \\
\hline \multicolumn{5}{|l|}{ Anemia } \\
\hline Yes & $22(59.5)$ & $15(40.5)$ & 37 & 7.99 \\
\hline No & $62(14.5)$ & $364(85.5)$ & 426 & 92.01 \\
\hline \multicolumn{5}{|l|}{ Other DM complication } \\
\hline Yes & $43(24.2)$ & $135(75.8)$ & 178 & 38.44 \\
\hline No & $34(11.9)$ & $251(88.1)$ & 285 & 61.56 \\
\hline \multicolumn{5}{|l|}{ Baseline medication } \\
\hline Dietary modification & $4(13.8)$ & $25(86.2)$ & 29 & 6.26 \\
\hline One oral agent & 47 (15.9) & $249(84.1)$ & 296 & 63.93 \\
\hline$>1$ Oral agent & $17(21.5)$ & $62(78.5)$ & 79 & 17.06 \\
\hline Insulin & $9(15.3)$ & $50(84.7)$ & 59 & 12.74 \\
\hline \multicolumn{5}{|l|}{ SBP } \\
\hline$\leq 140$ & $62(16.5)$ & $313(83.5)$ & 375 & 80.99 \\
\hline$>140$ & $15(17.1)$ & $73(82.9)$ & 88 & 19.01 \\
\hline \multicolumn{5}{|l|}{ DBP } \\
\hline$\leq 90$ & $69(16.7)$ & $344(83.3)$ & 413 & 89.20 \\
\hline$>90$ & $8(16.0)$ & $42(84.0)$ & 50 & 10.80 \\
\hline
\end{tabular}

$D B P$ diastolic blood pressure; $D M$ diabetes mellitus; $D N$ diabetic neuropathy; SBP systolic blood pressure

In line with studies conducted in Tanzania [14], China [18], and India [19], the present study documented that the hazard of diabetic neuropathy was increased with the increase of age. It might be related to the three main alterations involved in the pathologic changes of diabetic neuropathy; inflammation, oxidative stress, and mitochondrial dysfunction [20], and all of these alterations are related to the process of aging [21].
The present study reported that the risks of developing diabetic neuropathy were increased among anemic patients as compared to non-anemic patients. This finding is consistent with other previous study [22]. The possible explanation for such consistent finding, anemia is considered to be associated with oxidative stress [23] which is also an important mechanism of diabetic neuropathy [24]. 


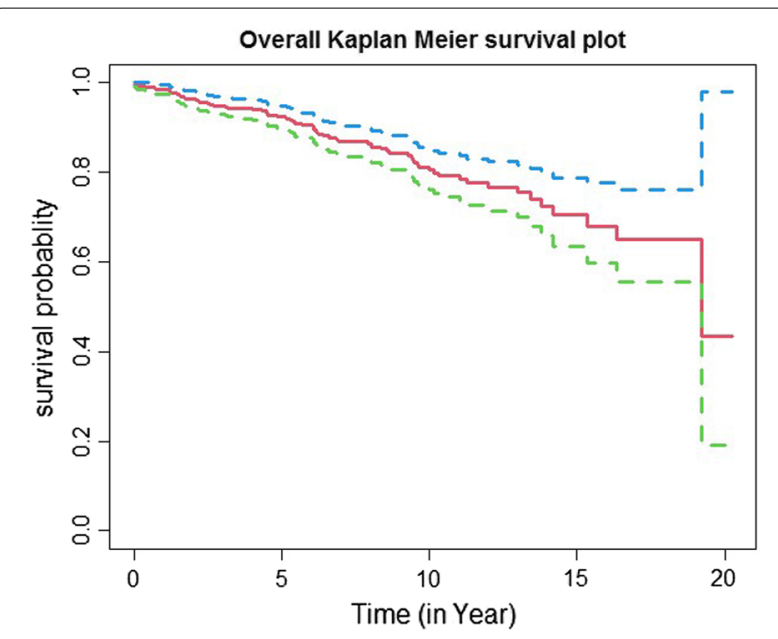

Fig. 1 Plot of the overall estimate of Kaplan-Meier for time to diabetic neuropathy among T2DM patients. The red line indicated the survival estimate, the blue and green colour line show the upper and the lower boundary of the estimate

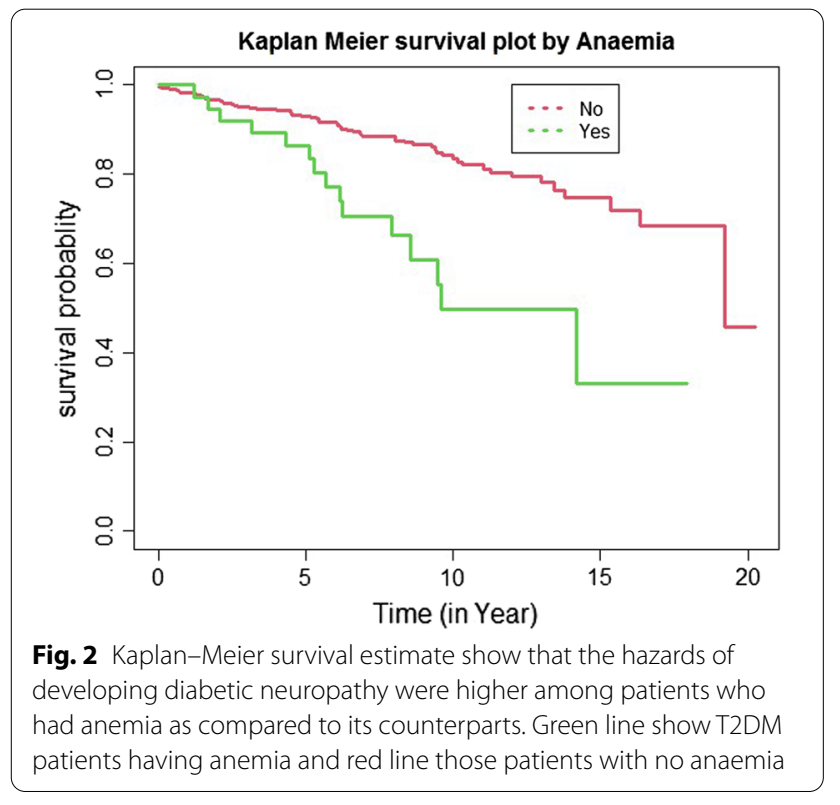

According to the present study, the hazards of developing diabetic neuropathy were increased among newly diagnosed T2DM who had other DM complications than their counterparts. A similar result has been found in a systematic review [25]. This might due to the majority of diabetic complications have similar risk factor especially poor glycemic control and this leads to the co-existence of different diabetic complications.

As per the author's knowledge no follow-up study on the risk of diabetic neuropathy in type 2 diabetes was conducted in these study areas. As a result, this study
Table 2 Predictors of time to diabetic neuropathy among newly diagnosed T2DM patients in UGCSH, January 2001-February 2019

\begin{tabular}{|c|c|c|c|c|}
\hline Variable & $\begin{array}{l}\text { Event } \\
\text { (DN) }\end{array}$ & Censored & $\mathrm{CHR}[95 \% \mathrm{Cl}]$ & AHR $[95 \% \mathrm{Cl}]$ \\
\hline \multicolumn{5}{|l|}{ Gender } \\
\hline Female & 45 & 233 & 1 & 1 \\
\hline Male & 32 & 153 & $1.18[0.74,1.87]$ & $1.16[0.70,1.84]$ \\
\hline \multicolumn{5}{|l|}{ Age } \\
\hline $45-49$ & 10 & 74 & 1 & 1 \\
\hline $30-34$ & 1 & 5 & $1.57[0.20,12.30]$ & $2.16[0.27,17.26]$ \\
\hline $35-39$ & 6 & 25 & $1.57[0.57,4.36]$ & $2.15[0.76,6.13]$ \\
\hline $40-44$ & 6 & 44 & $0.74[0.25,2.19]$ & $0.87[0.29,2.58]$ \\
\hline $50-54$ & 12 & 65 & $1.22[0.52,2.83]$ & $1.29[0.54,3.05]$ \\
\hline $55-59$ & 11 & 64 & $1.34[0.56,3.18]$ & $1.36[0.57,3.25]$ \\
\hline $60-64$ & 12 & 49 & $1.40[0.59,3.33]$ & $1.02[0.41,2.54]$ \\
\hline $65-69$ & 14 & 31 & $3.14[1.38,7.16]$ & $2.78[1.20,6.46]$ \\
\hline$>70$ & 5 & 29 & $1.66[0.56,4.89]$ & $1.08[0.34,3.39]$ \\
\hline \multicolumn{5}{|l|}{ Duration of DM } \\
\hline $5-9$ & 35 & 187 & 1 & 1 \\
\hline $0-4$ & 67 & 15 & $3.20[1.64,6.26]$ & $3.77[1.82,7.76]$ \\
\hline $10-14$ & 22 & 110 & $0.45[0.25,0.81]$ & $0.43[0.24,0.80]$ \\
\hline$>14$ & 5 & 22 & $0.45[0.25,0.81]$ & $0.29[0.09,0.87]$ \\
\hline \multicolumn{5}{|l|}{ Hypertension } \\
\hline No & 55 & 301 & 1 & 1 \\
\hline Yes & 22 & 85 & $1.06[0.64,1.75]$ & $0.74[0.36,1.51]$ \\
\hline \multicolumn{5}{|l|}{ Anemia } \\
\hline No & 62 & 364 & 1 & 1 \\
\hline Yes & 22 & 15 & $3.16[1.79,5.58]$ & $3.82[1.66,8.82]$ \\
\hline \multicolumn{5}{|l|}{$\begin{array}{l}\text { Other DM com- } \\
\text { plication }\end{array}$} \\
\hline No & 34 & 251 & 1 & 1 \\
\hline Yes & 43 & 135 & $1.82[1.15,2.88$ & $1.68[1.03,2.76]$ \\
\hline \multicolumn{5}{|c|}{$\begin{array}{l}\text { Baseline medica- } \\
\text { tion }\end{array}$} \\
\hline One oral agent & 47 & 249 & 1 & 1 \\
\hline $\begin{array}{l}\text { Dietary modifi- } \\
\text { cation }\end{array}$ & 4 & 25 & $0.80[0.29,2.23]$ & $1.13[0.39,3.27]$ \\
\hline$>1$ Oral agent & 17 & 62 & $2.27[1.28,4.01]$ & $1.63[0.89,2.97]$ \\
\hline Insulin & 9 & 50 & $1.01[0.49,2.07]$ & $0.76[0.36,1.60]$ \\
\hline \multicolumn{5}{|l|}{ SBP } \\
\hline$\leq 140$ & 62 & 313 & 1 & 1 \\
\hline$>140$ & 15 & 73 & $0.89[0.50,1.57]$ & $0.94[0.46,1.92]$ \\
\hline \multicolumn{5}{|l|}{ DBP } \\
\hline$\leq 90$ & 69 & 344 & 1 & 1 \\
\hline$>90$ & 8 & 42 & $0.77[0.37,1.61]$ & $1.30[0.51,3.32]$ \\
\hline
\end{tabular}

$A H R$ adjusted hazard ratio; $C H R$ crud hazard ratio; $C l$ confidence interval; $D B P$ diastolic blood pressure; $D M$ diabetes mellitus; $D N$ diabetic neuropathy; SBP systolic blood pressure

may give a basis for the future studies. However, this study also has limitations that should be considered when interpreting the results. Since the current study used secondary data, some important variable like 
baseline fasting blood sugar, diabetic self-care activity, body mass index, cigarette smoking, hyperlipidaemia and micro-albuminuria were not included in the analysis. In addition, Diabetic neuropathy was not diagnosed using electrophysiological or NCS. This might be no sufficient to confirm diabetic neuropathy.

\section{Conclusion}

More than half of diabetic neuropathy cases were occurred within short period of diagnosed with T2DM. Significant predictors for the time to DN were old age, short duration of DM, having anaemia and other DM complication. Therefore, we recommend early screening for DM and its complication for risky groups. While doing that due consideration should be assumed for old $\&$ anemic patients.

\section{Abbreviations \\ AHR: Adjusted hazard ratio; CHR: Crud hazard ratio; Cl: Confidence interval; DBP: Diastolic blood pressure; DM: Diabetes mellitus; DN: Diabetic neuropathy; HMIS: Health management information system; IDF: International Diabetes Federation; KM: Kaplan-Meier; PHA: Proportional hazard assumptions; SBP: Systolic blood pressure; T2DM:Type 2 diabetes mellitus; WHO: World Health Organization.}

\section{Acknowledgements}

We would like to express our deepest gratitude to the University of Gondar for ethical approval and funding.

\begin{abstract}
Authors' contributions
Conception of the work, design of the work, acquisition of data, analysis and interpretation of data was done by SA. Data curation, drafting the article, revising it critically for intellectual content, validation and final approval of the version to be published was done by SA, BS AB, ZTT and TA. All authors read and approved the final manuscript.
\end{abstract}

\section{Funding}

No fund was received for this work.

\section{Availability of data and materials}

All necessary information's were included with in the manuscript.

\section{Declarations}

\section{Ethics approval and consent to participate}

Ethical clearance and letter of cooperation was obtained from the institutional review board of the University of Gondar with reference number of IPH/160/05/2011. Then, permission letters from officials of University of Gondar Comprehensive Specialized Hospital, Department of Internal Medicine were processed before data collection. No personal identifiers, such as name, address and no private information was collected. Confidentiality during all phases of research activities was kept and data was held on secured password protected system.

\section{Consent for publication}

Not applicable.

\section{Competing interests}

The authors have declared that no competing interests exist.

\section{Author details}

${ }^{1}$ Department of Epidemiology and Biostatistics, Institute of Public Health, College of Medicine and Health Sciences, University of Gondar, Gondar, Ethiopia. ${ }^{2}$ Departments of Epidemiology and Biostatistics, Collage of Health and Medical Sciences, Haramaya University, Haramaya, Ethiopia.

Received: 9 November 2020 Accepted: 17 October 2021 Published online: 30 October 2021

\section{References}

1. King H, Aubert RE, Herman WHJD. Global burden of diabetes, 1995-2025: prevalence, numerical estimates, and projections. Diabetes Care. 2019;21(9):1414-31.

2. Powers AC, Worku D. Diabetes mellitus. In: Kasper D, Fauci A, Hauser S, Longo D, Jameson J, Loscalzo J, editors. Harrison's principles of internal medicine. 17th ed. New York: Mcgraw-Hill; 2008.

3. Sadikot S, Nigam A, Das S, Bajaj S, Zargar A, Prasannakumar K, et al. The burden of diabetes and impaired glucose tolerance in India using the WHO 1999 criteria: prevalence of diabetes in India study (PODIS). Diabetes Res Clin Pract. 2004;66(3):301-7.

4. Zeng L, Alongkronrusmee D, van Rijn RM. An integrated perspective on diabetic, alcoholic, and drug-induced neuropathy, etiology, and treatment in the US. J Pain Res. 2017;10:219.

5. Vinik Al, Nevoret M-L, Casellini C, Parson HJE, Clinics M. Diabetic neuropathy. Endocrinol Metab Clin N Am. 2013;42(4):747-87.

6. Egland JD, Asbury AK. Peripheral neuropathy. Lancet. 2004;363(9427):2151-61.

7. Kengne AP, Echouffo-Tcheugui JB, Sobngwi E, Mbanya JCJH. New insights on diabetes mellitus and obesity in Africa-Part 1: prevalence, pathogenesis and comorbidities. Heart. 2013;99(14):979-83.

8. AI Washali AY, Azuhairi AA, Hejar AR, Amani YW. Prevalence and associated risk factors of diabetic peripheral neuropathy among diabetic patients in National Center of Diabetes in Yemen. Int J Publ Health Clin Sci. 2014;1(1):141-50.

9. Yeboah K, Puplampu P, Boima V, Antwi DA, Gyan B, Amoah AG. Peripheral sensory neuropathy in type 2 diabetes patients: a case control study in Accra, Ghana. J Clin Transl Endocrinol. 2016;5:26-31.

10. Abdissa D, Hamba N, Kene K, Bedane DA, Etana G, Muleta D, et al. Prevalence and determinants of peripheral neuropathy among type 2 adult diabetes patients attending Jimma University Medical Center, Southwest Ethiopia, 2019, an Institutional-Based Cross-Sectional Study. J Diabetes Res. 2020. https://doi.org/10.1155/2020/9562920.

11. Jember G, Melsew YA, Fisseha B, Sany K, Gelaw AY, Janakiraman BJJOD, et al. Peripheral sensory neuropathy and associated factors among adult diabetes mellitus patients in Bahr Dar, Ethiopia. J Diabetes Metab Disorders. 2017;16(1):16.

12. Boulton AJ, Vinik Al, Arezzo JC, Bril V, Feldman EL, Freeman R, et al. Diabetic neuropathies: a statement by the American Diabetes Association. Diabetes Care. 2005;28(4):956-62.

13. Dyck PJ, Albers JW, Andersen H, Arezzo JC, Biessels GJ, Bril V, et al. Diabetic polyneuropathies: update on research definition, diagnostic criteria and estimation of severity. Diabetes Metab Res Rev. 2011;27(7):620-8.

14. Amour AA, Chamba N, Kayandabila J, Lyaruu IA, Marieke D, Shao ER, et al. Prevalence, patterns, and factors associated with peripheral neuropathies among diabetic patients at tertiary hospital in the Kilimanjaro Region: descriptive cross-sectional study from North-Eastern Tanzania. Int J Endocrinol. 2019;2019:5404781.

15. Kisozi T, Mutebi E, Kisekka M, Lhatoo S, Sajatovic M, Kaddumukasa M, et al. Prevalence, severity and factors associated with peripheral neuropathy among newly diagnosed diabetic patients attending Mulago hospital: a cross-sectional study. Afr Health Sci. 2017;17(2):463-73.

16. Nisar MU, Asad A, Waqas A, Ali N, Nisar A, Qayyum MA, et al. Association of diabetic neuropathy with duration of type 2 diabetes and glycemic control. Cureus. 2015;7(8):e302.

17. Khawaja N, Abu-Shennar J, Saleh M, Dahbour SS, Khader YS, Ajlouni KM. The prevalence and risk factors of peripheral neuropathy among patients with type 2 diabetes mellitus; the case of Jordan. Diabetol Metab Syndr. 2018;10(1):8. 
18. Mao F, Zhu X, Liu S, Qiao X, Zheng H, Lu B, et al. Age as an independent risk factor for diabetic peripheral neuropathy in Chinese patients with type 2 diabetes. Aging Dis. 2019;10(3):592.

19. Dsouza M, Kulkarni V, UnnikrishnanBhaskaran HA, Naimish H, Prakash A, Tabreez S, et al. Diabetic peripheral neuropathy and its determinants among patients attending a tertiary health care centre in Mangalore, India. J Public Health Res. 2015;4(2):1

20. Román-Pintos LM, Villegas-Rivera G, Rodríguez-Carrizalez AD, MirandaDíaz AG, Cardona-Muñoz EG. Diabetic polyneuropathy in type 2 diabetes mellitus: inflammation, oxidative stress, and mitochondrial function. J Diabetes Res. 2016;2016:3425617.

21. Corriere M, Rooparinesingh N, Kalyani RR. Epidemiology of diabetes and diabetes complications in the elderly: an emerging public health burden Curr Diabetes Rep. 2013;13(6):805-13.

22. Wu F, Jing Y, Tang X, Li D, Gong L, Zhao H, et al. Anemia: an independent risk factor of diabetic peripheral neuropathy in type 2 diabetic patients. Acta Diabetol. 2017;54(10):925-31.
23. Grune T, Sommerburg O, Siems W. Oxidative stress in anemia. Clin Nephrol. 2000;53(1 Suppl):S18.

24. Albers JW, Pop-Busui R. Diabetic neuropathy: mechanisms, emerging treatments, and subtypes. Curr Neurol Neurosci Rep. 2014;14(8):473.

25. Li J, Cao Y, Liu W, Wang Q, Qian Y, Lu P. Correlations among diabetic microvascular complications: a systematic review and meta-analysis. Sci Rep. 2019;9(1):3137

\section{Publisher's Note}

Springer Nature remains neutral with regard to jurisdictional claims in published maps and institutional affiliations.

\section{Submit your manuscript to a SpringerOpen ${ }^{\circ}$ journal and benefit from:}

- Convenient online submission

- Rigorous peer review

- Open access: articles freely available online

- High visibility within the field

- Retaining the copyright to your article

Submit your next manuscript at $\boldsymbol{\nabla}$ springeropen.com 